International Journal of Food Science, Nutrition and Dietetics (IJFS)

ISSN 2326-3350

\title{
Medicinal Mushrooms as a Source of Novel Functional Food
}

Prasad $\mathrm{S}^{1 *}$, Rathore $\mathrm{H}^{1}$, Sharma $\mathrm{S}^{1}$, Yadav $\mathrm{AS}^{2}$

${ }^{1}$ Centre for Rural Development and Technology, Indian Institute of Technology, Delhi, India.

${ }^{2}$ Haryana Agro Industries Corporation Limited, Haryana, India.

\begin{abstract}
Mushrooms are higher fungi having great taste and nutraceutical properties. They are one such dietary component that can help us in addressing the issues of quality food, health and environmental sustainability. Due to the presence of a large number of secondary metabolites mushrooms can be used as a source for biotherapeutics which in turn can help in development of new drugs. There has been a recent upsurge of interest in mushrooms not only as a health food which is rich in protein but also due to the presence of biologically active compounds of medicinal value which possess antioxidative, anticancer, antiviral, hepatoprotective, immunomodulating and hypocholesterolemic properties. Hence, mushrooms are used as a dietary supplements as wells as therapeutic agents in complementary medicine. Edible items can be fortified with mushrooms owing to their high nutritive value and such food serve as a nutrient reservoir for malnourished populations. The potential therapeutic implications of mushrooms are enormous however; detailed mechanisms of various health benefits of mushrooms to humans still require intensive investigation, especially with the emergence of new evidence of their health benefit. The paper outlines the information on all such aspects of medicinal mushrooms along with their role in various diseases and in the area of clinical nutrition.
\end{abstract}

Keywords: Mushrooms; Neutraceuticals; Active Compounds; Medicines.

\section{*Corresponding Author:}

Shalinee Prasad,

Centre for Rural Development and Technology, Indian Institute of Technology, Delhi, India.

E-mail: shalinee013@gmail.com

Recieved: September 07, 2015

Accepted: October 09, 2015

Published: October 20, 2015

Citation: Prasad S, Rathore H, Sharma S, Yadav AS (2015) Medicinal Mushrooms as a Source of Novel Functional Food. Int J Food Sci Nutr Diet. 04(5), 221-225. doi: http://dx.doi.org/10.19070/2326-33501500040

Copyright: Prasad S ${ }^{\odot}$ 2015. This is an open-access article distributed under the terms of the Creative Commons Attribution License, which permits unrestricted use, distribution and reproduction in any medium, provided the original author and source are credited.

\section{Introduction}

India has witnessed an enormous change in its agricultural pattern due to the continuous increase in the population rate. Henceforth, rapid rise of the population brings forward the challenge of meeting the demands of quality food and achieving nutritional security. Wide spread malnutrition necessitated the search for alternative source of protein since the production of pulses has not kept pace with the requirement of the country [1]. The rising demand for functional food free from synthetic chemicals indicates the awareness of people on quality food. The excellent texture and unique flavour of edible and medicinal mushrooms makes them universally accepted by all age groups [2]. Due to the pro- duction of a large variety of secondary metabolites with exceptional chemical structures and interesting biological actions they are reservoir of valuable chemical resources [3]. However, there is very little awareness on mushrooms as a healthy food and as an important source of biological active substances with medicinal value [4].

For hundreds of years, medicinal mushrooms as medicinal extract and essences, and are applied as alternative medicine in Korea, China, Japan and eastern Russia [5]. According to current estimates, mushrooms constitute at least 12,000 species worldwide and out of that 2,000 species are reported as edible. About 35 edible mushroom species are commercially cultivated whereas nearly 200 wild species used for medicinal purposes [6]. The most cultivated mushroom worldwide is Agaricus bisporus, followed by Lentinula edodes, Pleurotus spp. and Flammulina velutipes [6, 7]. Mushrooms contain a high moisture percentage that ranges between 80 and $95 \mathrm{~g} / 100 \mathrm{~g}$, approximately. They are a rich source of protein, 200-250 g/kg of dry matter; leucine, valine, glutamine, glutamic and aspartic acids are the most abundant. They are low-calorie foods because of their low fat content, $20-30 \mathrm{~g} / \mathrm{kg}$ of dry matter, being linoleic (C18:2), oleic (C18:1) and palmitic (C16:0) the main fatty acids. Edible mushrooms contain high amounts of ash, $80-120 \mathrm{~g} / \mathrm{kg}$ of dry matter and are rich in minerals like potassium, phosphorus, magnesium, calcium, copper, iron, and zinc). Carbohydrates present in them include chitin, glycogen, trehalose, and mannitol; besides, they contain fiber, beta- glucans, hemicelluloses, and pectic substances [8]. The nutritive value of some commonly known mushroom varieties is listed in Table 1.

Medicinal mushrooms have been demonstrated to produce ben- 
Table1. Nutritional value of some edible mushrooms (dry basis).

\begin{tabular}{|c|c|c|c|c|c|}
\hline Mushroom species & Protein \% & Fat \% & Ash \% & Carbohydrates \% & Energy kcal/kg \\
\hline Agaricus bisporus & 14.1 & 2.2 & 9.7 & 74.0 & 325 \\
\hline Lentinus edodes & 4.5 & 1.73 & 6.7 & 87.1 & 772 \\
\hline Pleurotus ostreatus & 7.0 & 1.4 & 5.7 & 85.9 & 416 \\
\hline Pleurotus eryngii & 11.0 & 1.5 & 6.2 & 81.4 & 421 \\
\hline Pleurotus sajor-caju & 37.4 & 1.0 & 6.3 & 55.3 & - \\
\hline Flammulina velutipes & 3.87 & 2.89 & 7.2 & 85.99 & 467 \\
\hline Hypsizigus marmoreus & 21.0 & 5.62 & 8.26 & 65.6 & - \\
\hline
\end{tabular}

Carneiro et al. 2013 [11]; Kalač 2013 [12]; Phan et al. 2012 [13]; Reis et al. 2012 [14].

eficial effects not only as a drug but also as a novel class of products variously known as functional food, nutraceuticals, dietary supplements that produce health benefits. Numerous studies have shown that regular intake of mushrooms or their products is effective both in preventing and treating specific diseases [9] (Table 2). Mushroom protein is comparable to muscle protein as it contains all the nine essential amino acids required by humans [9]. Since they provide all the essential amino acids they are used in the vegetarian diets and are a good option for those who do not consume meat products. The edible class of mushrooms that shows potential medicinal and functional properties includes Lentinus, Auricularia. Hericium, Grifola, Flammulina, Pleurotus, and Tremella. The other species known only for their medicinal properties include Ganoderma and Trametes [10].

\section{Therapeutic Potential of Mushrooms}

The knowledge of the relationship between diet and disease has led to the development of all together a new scientific discipline which is termed as "functional food science." Functional foods can be anything like dietary supplements, medicinal foods, vita foods, phytochemicals, and myochemicals and also pharmafood, which could be used specifically to improve the health. Mushrooms falls very well into this category of functional foods as it has all the potential to ameliorate diseases. 'Mushroom Nutraceuticals' are the traditional preparations which were used in ancient times in the form of extracts, health tonics, concentrates, fermented beverages, tinctures, teas, soups, herbal formula, powders and arid healthful food dishes [16]. The term "Mushroom Nutraceuticals" has been coined by Chang and Buswell [17]. Due to their immunomodulatory action, they boosts the immune system [18] by the activation of dendritic cells, NK cells, T-cells, macrophages, and production of cytokines [19] and have curative actions against a lot of degenerative diseases without having any side effects; unlike the ones involved in the usage of synthetic drugs. Studies have shown that regular consumption of mushrooms or their products is effective both in preventing and treating specific diseases [7].

Edible mushrooms and their constitutive active compounds have been described to have beneficial effects on hyperglycemia and hypercholesterolemia [20, 21]. Several mushrooms have high content of acidic polysaccharides, dietary fiber, and antioxidants, including vitamins C, B12, and D; folate ergothioneine; and polyphenol [22] suggesting that the mushroom may have potential anti-inflammatory, hypoglycaemic and hypocholesterolemic effects (Table 3). The significant pharmacological effects and physiological properties of mushrooms are bio regulation (immune enhancement), maintenance of homeostasis and regulation of biorhythm, cure of various diseases and prevention and improvement from life threatening diseases such as cancer, cerebral stroke and heart diseases. Mushrooms are also known to have effective substances for antifungal, anti-inflammatory, antitumor, antiviral, antibacterial, hepatoprotective, antidiabetic, hypolipidemic, antithrombotic and hypotensive activities [18].

Mushrooms are known to complement chemotherapy and radiation therapy by countering the side-effects of cancer, such as nausea, bone marrow suppression, anemia, and lowered resistance. Recently, a number of bioactive molecules, including anti-tumor agents have been identified from various mushrooms. Some of the identified molecules are $\beta$-glucan, proteoglycan, lectin, phenolic compounds, flavonoids, volatile oils, tocopherols, phenolics, flavonoids, carotenoids, folates, ascorbic acid enzymes, and organic acids [23] , polysaccharides, triterpenoids, dietary fibre, lentinan, schizophyllan, lovastatin, pleuran, steroids, glycopeptides, terpenes, saponins, xanthones, coumarins, alkaloid, kinon, fenil propanoid, kalvasin, porisin, AHCC, maitake D-fraction, ribonucleases, eryngeolysin, and also have been effectual against various types of diseases[24, 25].

The active components in mushrooms responsible for conferring anti-cancer potential are lentinan, krestin, hispolon, lectin, calcaelin, illudin S, psilocybin, Hericium polysaccharide A and B (HPA and HPB), ganoderic acid, schizophyllan, laccase, etc [26]. The bioactive compounds present in mushrooms can be classified into secondary metabolites, glycoproteins and polysaccharides. Out of all these, mushroom polysaccharides are the best known and most potent mushroom-derived substances with anti-tumor and immunomodulating properties. The mushroom polysaccharide i.e beta glucans are the most versatile bioactive molecule owing to its excellent therapeutic implications and broad spectrum biological activity. Since the $\beta$-Glucans are not amalgamated by humans, so these compounds are recognized by our immune systems as non-self molecules that induces both innate and adaptive immune responses [8].

\section{Novel Mushroom Biotech Products}

Mushrooms produced are not only food but are raw material for development of functional food and dietary supplements (nutraceuticals) for health and quality life of humans. Inclusion of mushrooms as functional food can help in the early intervention of sub-healthy states in humans and it might prevent the consequences of life threatening diseases. Trametes versicolor contains proteoglycan constituents like Krestin (PSK) and polysaccharide peptide (PSP). Both of these glycans have been used in cancer therapy like gastric, colorectal lung cancer and breast cancer [27, 
Table 2. Some commonly consumed mushrooms along with their bioactive molecules.

\begin{tabular}{|c|c|c|}
\hline Biological name of mushroom & Active principle/constituents/extracts & Activity reported \\
\hline Agaricus bisporus & Fibers, lectins & Hypocholesterolemic, Hypoglycemic \\
\hline Boletus edulis Bull & Extracts of fruiting bodies & Antitumor \\
\hline Flammulina velutipes (Curtis) Singer & Fibers, ethanolic extracts & Antioxidant, Hypocholesterolemic, Antiallergic \\
\hline Grifola frondosa (Dicks.) Gray & MD-fraction, ergosterol & $\begin{array}{l}\text { Antioxidant, hypotensive, Hypoglycemic, Im- } \\
\text { munotherapy, Antiinflammatory activity }\end{array}$ \\
\hline Ganoderma lucidum (Curtis) P. Karst & $\begin{array}{c}\text { Ganoderan } \mathrm{A} \text { and } \mathrm{B} \text {, glucans, Triterpenes, } \\
\text { ganosporeric acid } \mathrm{A} \text {, ganopoly, the polysaccha- } \\
\text { ride-containing preparation }\end{array}$ & $\begin{array}{l}\text { Hypoglycemic, antioxidant and antitumor, } \\
\text { antiviral (HIV-1), Antiallergic Anti-inflamma- } \\
\text { tory antihepatotoxic, inhibit the biosynthesis } \\
\text { of cholesterol, antioxidative and free radical } \\
\text { scavenging effects. }\end{array}$ \\
\hline Hypsizigus marmoreus & Ethanolic extracts & Antioxidant, Antiallergic \\
\hline Lentinula edodes (Berk.) Pegler & $\begin{array}{c}\text { Methanolic and water extracts, eritadenine, } \\
\text { lentinan, oxalic acid, ethanolic mycelial ex- } \\
\text { tracts. }\end{array}$ & $\begin{array}{c}\text { Antioxidant, Hypocholesterolemic, Immuno- } \\
\text { therapy, Antimicrobial, antiprotozoal }\end{array}$ \\
\hline Pleurotus ostreatus & Water and 30\% ethanolic extract & Antioxidant, Hypocholesterolemic \\
\hline Pleurotus eryngii & Ethanolic extracts & Antiallergic \\
\hline Volvariella volvacea & Methanolic and water exopolysaccharides & Antioxidant, Hypocholesterolemic \\
\hline
\end{tabular}

Rathee et al., 2012 [15]

Table 3. Nutraceutical potential of the some important mushrooms.

\begin{tabular}{|c|c|c|c|}
\hline Mushroom Species & Active Constituents & $\begin{array}{c}\text { Type of } \\
\text { polysaccharides }\end{array}$ & Medicinal Properties \\
\hline Agaricus bisporous & Lectins & Heteropolysaccharides & $\begin{array}{c}\text { Enhance insulin secretion, anti-aging } \\
\text { property. }\end{array}$ \\
\hline Auricularia auricula & Acidic Polysaccharides & Homopolysaccharides & $\begin{array}{l}\text { Anti-tumour activities, lowers cho- } \\
\text { lesterol, triglycerides, and lipid levels; } \\
\text { decrease blood glucose, beneficial in } \\
\text { coronary heart disease, immune } \\
\text { tonic. }\end{array}$ \\
\hline Cordyceps sinensis & Cordycepin & Heteropolysaccharides & $\begin{array}{l}\text { Cure lung infections, hypoglycemic } \\
\text { activity, cellular health properties, } \\
\text { anti- depressant activity. }\end{array}$ \\
\hline Ganoderma lucidum & $\begin{array}{l}\text { Polysaccharides, triterpenoids, } \\
\text { germanium, nucleotides and } \\
\text { nucleosides, Ganoderic acid, } \\
\text { Beta-glucan, }\end{array}$ & Heteropolysaccharides & $\begin{array}{l}\text { Augments immune system, liver } \\
\text { protection, antibiotic } \\
\text { properties, inhibits cholesterol } \\
\text { synthesis; immunomodulatory, anti- } \\
\text { cancerous properties. }\end{array}$ \\
\hline Grifola frondosa & Grifloan, Lectins & Heteroploysaccharides & $\begin{array}{l}\text { Increases insulin secretion, decrease } \\
\text { blood glucose, improves ovulation. }\end{array}$ \\
\hline Trametes versicolor & $\begin{array}{l}\text { Polysaccharide-K } \\
\text { (Krestin), Coriolon } \\
\text { and glycoproteins }\end{array}$ & Heteropolysaccharides & $\begin{array}{l}\text { Decrease immune system depres- } \\
\text { sion, prevents cancer, } \\
\text { inhibits growth of Candida albicans, } \\
\text { anti- viral activity by inhibiting the } \\
\text { replication of HIV, liver protective } \\
\text { functions. }\end{array}$ \\
\hline Volvariella volvacea & Glycoproteins & Heteropolysaccharides & $\begin{array}{c}\text { Cardio-protective, lowers blood } \\
\text { pressure. }\end{array}$ \\
\hline
\end{tabular}

Lakhanpal and Rana, 2005; [5] 
28]. Extract from Chaga mushroom (Inonotus obliquus) befungin is approved as an antitumour drug in Russia owing to its capability in curing certain cancers like breast, lung, cervical, and stomach cancers [29]. Biotech products Hericium erinaceus mushrooms have been extensively used in treating Alzheimer diseases. Hericenones from the fruit bodies and erinancines from the mycelium of this mushroom have induced the expression of neurotrophic factors such as nerve growth factor (NGF) in astrocytes [27]. Healthy food developed from biotechnologically cultivated mycelia of medicinal edible mushrooms and Tremella spp. in combination with other natural substances (medicinal plants, algae, etc.) possesses antioxidant and immune-stimulating activity and blood glucose and lipid controlling effects [29, 30]. Existing biotech-products from $H$. erinaceus help to control and bleeding. Since some mushroom products are able to decrease high glucose and lipid levels in blood they are recommended as neuro-and vasotonics, hepatoprotective and thrombolytic agents [31]. There are certain commercial mushroom dietary supplements which are produced all around the world and are consumed by the people. A list of such products is provided in Table 4 .

\section{Conclusion}

Mushrooms contain numerous substances including glycoproteins, glyconutrients, lectins, etc. The compounds they contain have been classified under the Host Defense Potentiators (HDP) which can have immune system enhancement properties. That is one of the reasons they are currently used as adjuncts to cancer treatments in Japan and China. Fungal polysaccharides are the most potent mushroom-derived substances with antitumor and immune-modulating properties. They are present in cell wall with different types of glycosidic linkages, such as $(1,3)$ and $(1,6)-\beta$-D-glucans. Several different polysaccharides anti tumor agents have been developed from the fruiting body, mycelia, and culture medium of various medicinal mushrooms (Lentinus edodes, Ganoderma lucidum, Schizophyllum commune, Trametes versicolor, Inonotus obliquus, and Flammulina velutipes). Further sustainable research of natural and genetic resources of medicinal mushrooms using enhanced screening methods of genomics, proteomics and metabolomics will assist in the biotechnological cultivation and usage of their bioactive molecules to develop novel healthcare biotech products with a encouraging universal impact on human welfare and environmental conservation. In a country like ours, medicinal mushrooms can eradicate the problems of malnutrition thereby ensuring nutrition security for the coming generations by means of diet fortification and nutraceuticals.

\section{Acknowledgements}

The authors thank University Grants Commission (UGC) for

Table 4. Overview of some mushroom dietary supplements.

\begin{tabular}{|c|c|}
\hline Product & Content \\
\hline Organic cordyceps sinesis & C.sinensis Alohaensis hybrid strain \\
\hline Gano super & Concentrated Reishi extracts \\
\hline Levolar Forte & $\begin{array}{c}\text { Extract of C.sinensis, fraction of G.frondosa, extract of coprinus comatus, } \\
\text { cinnamon extracts }\end{array}$ \\
\hline Fine Agaricus Gold & $\begin{array}{c}\text { Highly concentrated micropowder active ingredients, protein } \\
\text { bound polysaccharide of Agaricus }\end{array}$ \\
\hline Fine Mesima & $\begin{array}{c}\text { Micropulverized powder of dried Phellinus linteus } \\
\text { mushroom }\end{array}$ \\
\hline Breast Mate & $\begin{array}{c}\text { Phellinus lineteus fraction, Maitake PSX fraction, } \\
\text { Glycoprotein SX fraction, Broccoli sprouts extract, Green } \\
\text { Tea extract, Vitamin D }\end{array}$ \\
\hline Shiitake Gold & Lentinan, Beta glucan polysaccharide \\
\hline
\end{tabular}

providing financial support for this work.

\section{References}

[1]. Sharma PK, Gothalwal R (2010) Weed extract: Cheap source for better yield and biological efficiency of Pleurotus florida. Asian J Bio Sci 5(1): 10-12.

[2]. Manzi P, Aguzzi A, Pizzoferrato L (2001) Nutritional value of mushrooms widely consumed in Italy. Food Chemistry 73(3): 321-325.

[3]. Zjawiony JK (2004) Biologically active compounds from Aphyllophorales (Polypore) fungi. J Nat Prod 67(2): 300-310.

[4]. Cheung LM, Cheung PC, Ooi VE (2003) Antioxidant activity and total phenolics of edible mushroom extracts. Food Chemistry 81(2): 249-255.

[5]. Lakhanpal TN, Rana M (2005) Medicinal and nutraceutical genetic resources of mushrooms. Plant Genetic Resources: Characterization and Utilization 3(2): 288-303

[6]. Beulah GH, Margret AA, Nelson J (2013) Marvelous medicinal mushrooms. Inter J Pharma Bio Sci 3(1): 611-615.

[7]. Chang ST, Miles PG (2004) Mushrooms: Cultivation, nutritional value, medicinal effect, and environmental impact. (2nd edtn), CRC Press, USA.

[8]. Valverde ME, Hernández-Pérez T, Paredes-López O (2015) Edible Mushrooms: Improving Human Health and Promoting Quality Life. Inter J Microbiol 1-14. http://dx.doi.org/10.1155/2015/376387.
[9]. Aida FMNA, Shuhaimi M, Yazid M, Maaruf AG (2009) Mushroom as a potential source of prebiotics: a review. Trends in Food Science and Technology 20(1): 567-575.

[10]. Ganeshpurkar A, Rai G, Jain AP (2010) Medicinal mushrooms: Towards a new horizon. Pharmacogn Rev 4(8): 127-135.

[11]. Carneiro AA, Ferreira IC, Dueńas M, Barros L, da Silva R, et al. (2013) Chemical composition and antioxidant activity of dried powder formulations of Agaricus blazei and Lentinus edodes. Food Chem 138(4): 21682173.

[12]. Kalač P (2013) A review of chemical composition and nutritional value of wild-growing and cultivated mushrooms. J Sci Food Agric 93(2): 209-218.

[13]. Phan CW, Wong WL, David P, Naidu M, Sabaratnam V (2012) Pleurotus giganteus (Berk.) Karunarathna \& K.D. Hyde: nutritional value and in vitro neurite outgrowth activity in rat pheochromocytoma cells. BMC Complementary and Alternative Medicine 12(102): 1-11.

[14]. Reis FS, Barros L, Martins A, Ferreira IC (2012) Chemical composition and nutritional value of the most widely appreciated cultivated mushrooms: an inter-species comparative study. Food Chem Toxicol 50(2): 191-197.

[15]. Sushila R, Dharmender R, Deepti R, Vikash K, Permender R (2012) Mushrooms as therapeutic agents. Revista Brasileira de Farmacognosia 22(2): 459474.

[16]. Smith JE, Rowan NJ, Sullivan R (2002) Medicinal mushrooms: Their thera- 
peutic properties and current medical usage with special emphasis on cancer treatments. In Cancer Research EUA University of Strathclyde. 200-202.

[17]. Chang ST, Buswell JA (1996) Mushroom Nutriceuticals. World J Microbiol Biotechnol 12(5): 473-476

[18]. Wasser SP, Weis AL (1999) Medicinal properties of substances occurring in higher Basidiomycetes mushrooms: Current perspective (review). Int J Med Mushr 1(1): 31- 62.

[19]. Wasser SP (2014) Medicinal Mushroom Science: Current Perspectives, Advances, Evidences and Challenges. Biomed J 37(6): 345-356.

[20]. Tiwari AK (2004) Antioxidant: New generation therapeutic base for treatment of polygenic disorders. Curr Sci 86(8): 1092-1102.

[21]. Sharma JR (1995) Ecology and distribution of Hymenochaetaceae, in Hymenochaetaceae of India. Botanical Survey of India.

[22]. Leelavathy KM, Ganesh PN (2000) Polypores in Kerala. Daya Publishing House, India.

[23]. Patel S, Goyal A (2012) Recent developments in mushrooms as anti-cancer therapeutics: a review. 3 Biotech 2(1): 1-15.

[24]. Chihara G (1992) Immunopharmacology of Lentinan, a polysaccharide isolated from Lentinus edodes: its applications as a host defence potentiator. Int J Oriental Medicine 17(5): 57-77.

[25]. Wasser SP, Weis AL (1999) Therapeutic effects of substances occurring in higher Basidiomycetes mushrooms: a modern perspective. Crit Rev Immunol 19(1): 65-96.
[26]. Chen J, Seviour R (2007) Medicinal importance of fungal beta-(1->3) (1->6)-glucans. Mycol Res 111(Pt 6): 635-652.

[27]. Vikineswary S, Hui WK, Naidu M, David PR (2013) Neuronal Health Can Culinary and Medicinal Mushrooms Help. J Tradit Complement Med 3(1): 62-68.

[28]. Maehara Y, Tsujitani S, Saeki H, Oki E, Yoshinaga K, et al. (2012) Biological mechanism and clinical effect of protein-bound polysaccharide $\mathrm{K}$ (KRESTIN): review of development and future perspectives. Surg Today 42(1): 8-28.

[29]. Standish LJ, Wenner CA, Sweet ES, Bridge C, Nelson A, et al. (2008) Trametes versicolor mushroom immune therapy in breast cancer. J Soc Integr Oncol 6(3): 122-128.

[30]. Khan MA, Tania M, Liu R, Rahman MM (2013) Hericium erinaceus: an edible mushroom with medicinal values. J Complement Integr Med 10(1): $1-6$.

[31]. Badalyan SM (2014) Potential of mushroom bioactive molecules to develop health care biotech products. Proceedings of the 8th International Conference on Mushroom biology and Mushroom Products.

[32]. Humberto JM, Llauradó G, BeltránY, Lebeque Y, Bermúdez RC, et al. (2015) The use of mushrooms in the development of functional foods, drugs or nutraceuticals: Wild Plants, Mushrooms and Nuts: Functional Food Properties and Applications. 